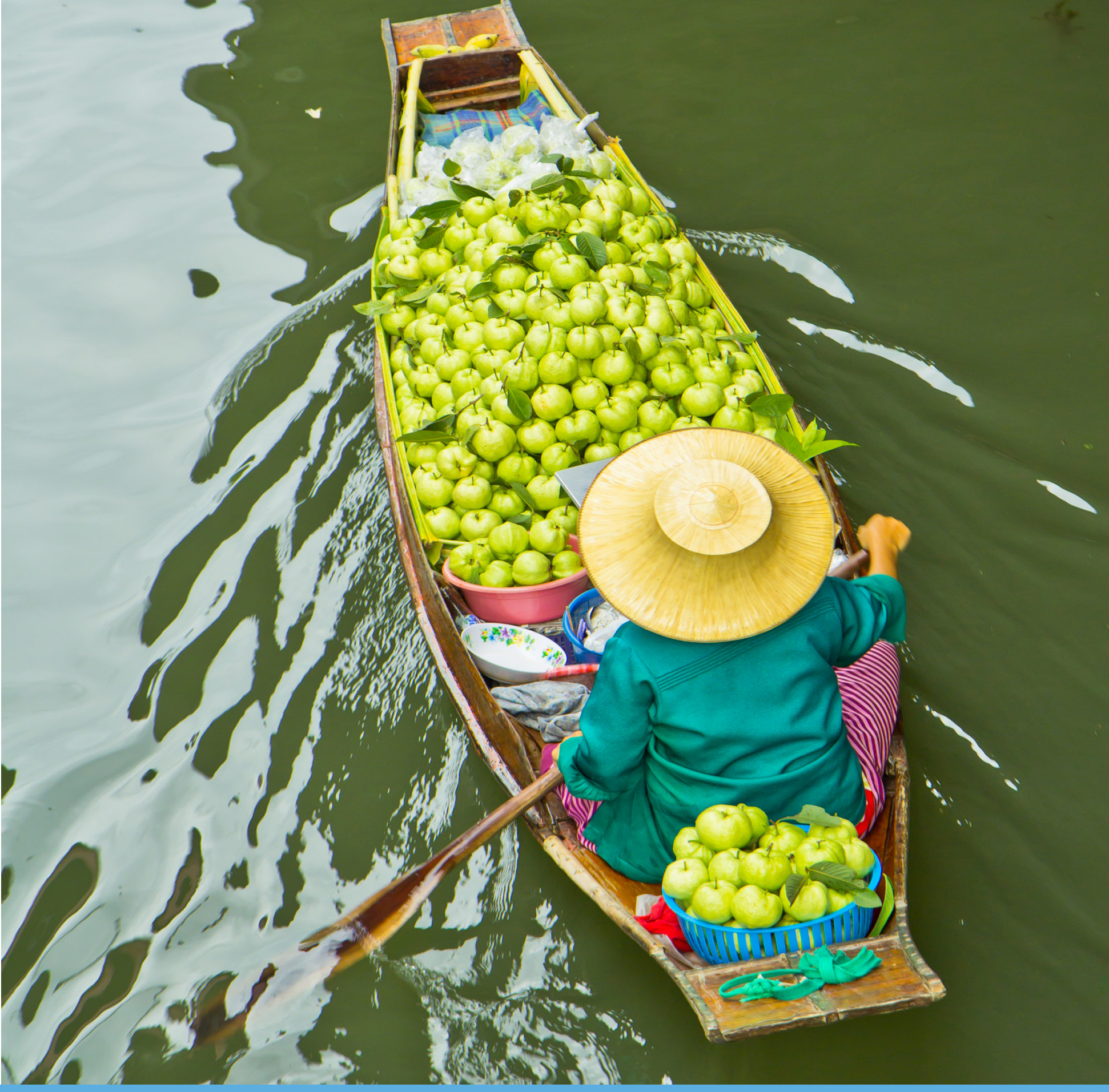

Transition Pathways - Contours of an Analytical Framework

Boelie Elzen, Wim de Haas, Seerp Wigboldus, Bram Bos, Marijke Dijkshoorn - Dekker

WAGENINGEN

UNIVERSITY \& RESEARCH 


\section{Transition Pathways - Contours of an Analytical Framework}

Boelie Elzen, Wim de Haas, Seerp Wigboldus, Bram Bos, Marijke Dijkshoorn - Dekker ${ }^{1}$

1 Wageningen University \& Research

This study was carried out by the Wageningen Research Foundation (WR) business unit Field Crops and was commissioned and by the Dutch Ministry of Agriculture, Nature and Food Quality within the context of the 'Food Security and Valuing Water' research theme of the Knowledge Base (project number KB-35-006-001).

WR is part of Wageningen University \& Research, the collaboration of Wageningen University and Wageningen Research Foundation.

Wageningen, June 2020

Report WPR-839 
Elzen, B., Haas, W. de, Wigboldus, S., Bos, B. Dijkshoorn - Dekker, M. 2019. Transition Pathways Contours of an Analytical Framework. Wageningen Research, Report WPR-839.

This report can be downloaded for free at https://doi.org/10.18174/525092

(C) 2020 Wageningen, Stichting Wageningen Research, Wageningen Plant Research, Business Unit Field Crops P.O. Box 430, 8200 AK Lelystad, The Netherlands; T +31 (0)320 2911 11; www.wur.eu/plantresearch

Chamber of Commerce no. 09098104 at Arnhem

VAT NL no. 8065.11.618.B01

Stichting Wageningen Research. All rights reserved. No part of this publication may be reproduced, stored in an automated database, or transmitted, in any form or by any means, whether electronically, mechanically, through photocopying, recording or otherwise, without the prior written consent of the Stichting Wageningen Research.

Stichting Wageningen Research is not liable for any adverse consequences resulting from the use of data from this publication.

Report WPR-839 


\section{Contents}

1

$\begin{array}{ll}\text { Key features of the project } & \\ \end{array}$

2.1 Introduction

2.2 System focus

2.3 Transitions to sustainability

2.4 Transition pathways

3.1 Introduction

3.2 Part 1: The Analytical Framework

3.2.1 Requirements of the AF 11

3.2.2 MLP: The macro dynamic of transitions 12

3.2.3 Zooming in: analysing micro-level dynamics in transitions 14

$\begin{array}{ll}3.2 .4 & \text { Operationalising sustainability }\end{array}$

$\begin{array}{ll}3.2 .5 & \text { Operationalisation for case study work }\end{array}$

$\begin{array}{lll}3.3 & \text { Part 2: Exploring transition pathways } & 18\end{array}$

3.3.1 Focus on development process rather than outcomes 18

3.3.2 Application in TP workshops 19

3.4 Part 3: Reflection methodology 19

$\begin{array}{ll}\text { References } & \mathbf{2 1}\end{array}$

$\begin{array}{lll}\text { Annex } 1 & \text { Perspectives on Transitions } & 23\end{array}$

Annex 2 Socio-Ecological Transistions and the Multi level Perspective 25

$\begin{array}{lll}\text { Annex } 3 & \text { Guidelines for 'quick cases' } & 27\end{array}$ 



\section{Project ambition}

\section{Background}

Current configurations of food systems in many regions of the world are inadequate to solve complex questions regarding the SDGs on Zero Hunger, Responsible Production and Consumption, and Climate Action. Moreover, food systems must respond to increasing (urban) populations and changing societal demands. The focus regions of this project (primarily Asia and Africa) are facing rapidly changing and sometimes unpredictable effects. Examples include the broad-ranging effects of migration and climate change that prompt a reconsideration of agro-ecological concepts of production at landscape/regional levels, the growing shortage of fresh water, and (particularly in Africa) a fast-growing (urban) population that requires a supply of fresh and diversified food in cities. These challenges call for drastic and system-wide actions to transform and develop the current food systems into more appropriate forms.

The "Transition Pathways and Integral Findings" project (motif) from the KB programme Food and Water Security (KB-35) of Wageningen University and Research, hereafter called the 'TransPath' project, addresses the challenges of engaging and committing stakeholders during such transformations of food systems (cf. adjoining Box). Good stakeholder engagement requires an appropriately inclusive understanding of what a food system is, what range of outcomes (economic, social, environmental, cultural, etc.) its functioning may have, and the possible transition pathways available to that food system.
Transition Pathways: research questions

- What type of transition pathways contribute to the targeted configuration of food systems that effectively achieve food security, sustainability, inclusiveness, and resilience? (The other projects (motifs) in the KB 35 programme will address what current configurations of the food system look like and how they should change to meet the SDG Zero Hunger.)

- What concepts, theories of change, engagement strategies, and mechanisms underpinning different types of transition pathways (i.e. which intervention methods and tools do they use)?

- How do these pathways depend on the local/regional situation (specifically in relation to urban, rural, aquatic, delta)?

- What are effective methods of engaging stakeholders to contribute at different stages of a sustainable food system transition (conceptualisation/orientation, practice, evaluation)?

- How can we integrate different concepts, theories of change, engagement strategies and mechanisms in a framework that is able to evaluate current food systems as well as give guidance for the use of different approaches in specific situations?

In this report we will develop a practice-oriented framework that addresses different transition pathways in local, regional, and global perspectives. This framework brings together different concepts and tools relevant to transition pathways. Existing concepts can be enriched by the addition of new elements or linkages amongst approaches. Specific attention will be given to integrating insights from different domains, how they interact, and how they can be used. Special reference will be given to stakeholders as actors in the transitions, with focus on their behavioural change process(es) and incentives as well as personal and environmental motivation, drivers, and barriers.

The overall ambition of the project is to explore options for 1) understanding, and 2) engaging effectively and appropriately with transition pathways towards sustainable agro-food systems. The analysis of these options will be used to make recommendations for specific stakeholders (later to be identified) on how they can play appropriate and effective roles in transitions to sustainability.

In the KB-35 programme, the exploration of different types of transition pathways towards more sustainable futures in agro-food systems will be done in two steps:

1. Develop an initial analytical framework and apply this in a number of testcases to consider whether it matches information/research needs and the extent to which it is suitable for wider application and adapt it where needed. This report describes this initial framework.

2. Using the initial experiences and outputs presented here to do the following in the period 20202022:

Further develop and operationalise the initial analytical framework to be used in the other KB-35 motifs; 
- Explore wider insights on transition processes from literature, making this available to the other motifs;

- Enhance accessibility for the other motifs of appropriate tools and methods for engaging with transition processes;

- Develop new (innovative) methods and tools to support processes of engaging with transitions to sustainability, making this available to the other motifs.

This implies that the TransPath project faces a three-fold task:

1. To develop an analytical framework which enables a systematic exploration of the main challenges in current agro-food systems (envisioned transitions) in a number of cases (the other projects (motifs) in this KB programme);

2. To develop a methodology to facilitate the exploration of potential future transition pathways with stakeholders and principles for responsible transition pathways.

3. To reflect with stakeholders on these transition pathways to infer possibilities for intervention and strategic action.

Each of these tasks will be further elaborated below.

Before elaborating the analytical framework, we will first discuss some of key features of the project. In the next chapter we will discuss the overall research approach that comprises three elements, viz. the analytical framework, the reflection pathways approach and the reflection methodology. 


\section{Key features of the project ${ }^{1}$}

\section{$2.1 \quad$ Introduction}

The TransPath project seeks to contribute to processes to make agro-food more sustainable. To this end, it will build on insights and methods that have been developed in the research field of sustainability transitions and related fields. Before discussing the various relevant approaches, we will first discuss some of key features of the project, viz. the 'system' focus, the analysis of 'transitions' and the exploration of 'transition pathways' in the following three sub-sections.

\section{$2.2 \quad$ System focus}

When a specific process (e.g. an agricultural practice) causes (sustainability) problems, the typical approach is to improve that process via add-on measures. In many cases, however, such add-on measures create problems elsewhere. To address this more adequately requires more encompassing approaches in which problematic processes are not treated in an isolated way but seen as part of more encompassing 'systems'. Thus, in the case of agriculture we can talk of a 'farming system'².

Systems can be defined at various levels and in relation to various issues and which level is most adequate depends on the specific objectives of the research. In the TransPath project we are interested in contributing to transitions to sustainable food systems which are more encompassing but which include 'farming systems'.

Such a wider systems perspective includes the production and the consumption side of food and related services, as well as the governance approaches related to this. They therefore encompass not only technical elements but also non-technical aspects like the actors involved (producers, consumers, regulators), habits and preferences, relationships, etc. They are usually referred to as 'socio-technical' systems to distinguish them from 'purely' technical systems like, for instance, a power plant. Furthermore, a food system perspective also includes a perspective on socio-ecological systems, and is not limited to a view on human-technology interactions. Thus, a food system perspective encompasses a view on interacting social, technical, economic, ecological, and other systems.

\footnotetext{
${ }^{1}$ This section was written before reading Hall \& Dijkman (2019). Their argument, however, largely follows the same lines. We could embed our discussion a bit more in this source, e.g. by using some of their definitions.

2 The "International Farming Systems Association" (IFSA) studies such farming systems: http://ifsa.boku.ac.at/cms/index.php?id=2
} 
In the TransPath project we want to contribute to enhanced understanding about what is involved in seeing conditions regarding production, consumption and governance change in such a way that food systems become more sustainable overall, as well as in its constituent parts. To facilitate this, the unit of analysis in the project will be the 'agro-food system' or, rather, agro-food systems, in plural.

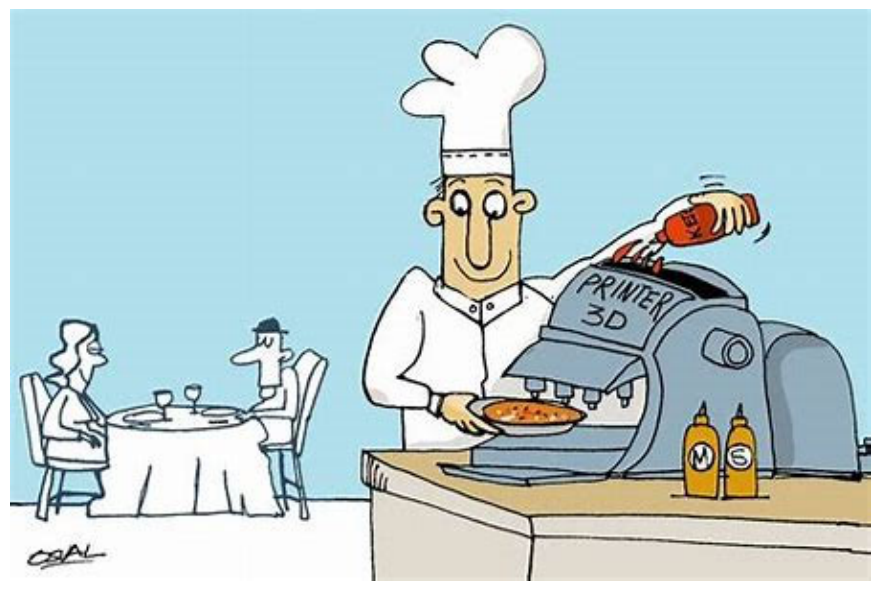

\subsection{Transitions to sustainability}

Seeking to contribute to sustainability in agro-food systems, this project focuses on 'transition processes'. What do we mean by this and how does this relate to more commonly used terms like change or innovation?

Agro-food systems are subject to continuous change (cf. Spaargaren et al. 2011). Much of this change is of an incremental nature and focusses on the production side, more specifically on the technological means by which crops and food are produced.

Taking a systems perspective, however, more encompassing and more radical forms of change come into view which affect not only the production side but also the consumption side and governance arrangements. E.g. people's diets could change by eating less beef which could drastically reduce the ecological footprint. Such more radical changes are called transitions and they are usually related to addressing root causes of experienced or anticipated challenges. Also, it may involve addressing the way power and politics play out in food systems in relation to how they may constrain transitions to sustainability.

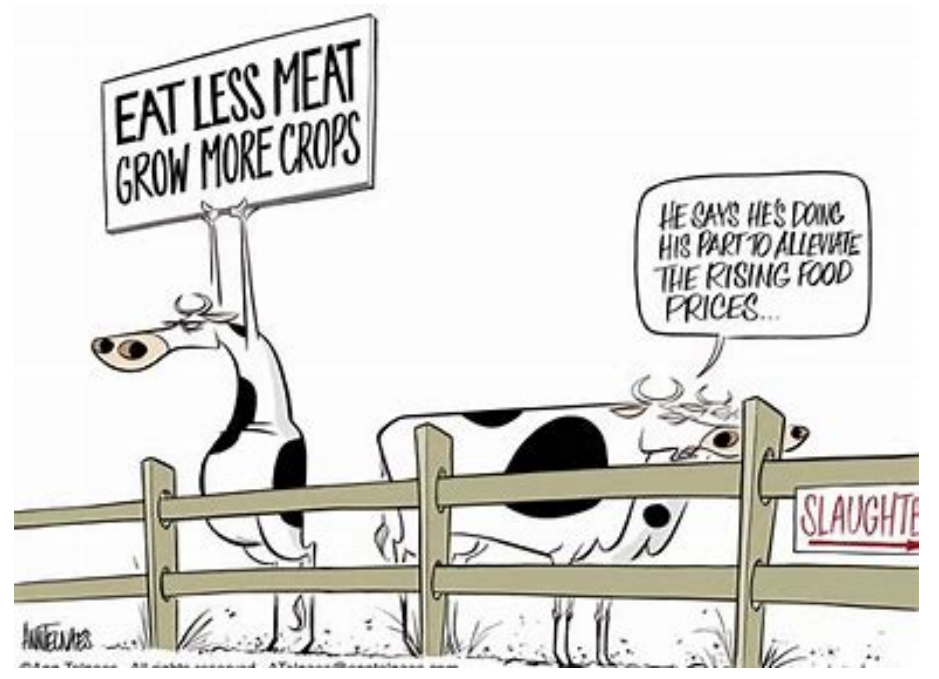


A critical aspect of a transition is that not only technology changes but also various non-technical aspects of a system. Thus, for instance, if a coal-fired power plant is replaced by a gas-fired power plant, this would not be called a transition. However, if this power plant is replaced by large scale introduction of PV panels on people's homes, this would be called a transition because consumers also become producers of energy (also addressed as 'prosumers'). So in a transition non-technical elements of the system also change.

A transition process is non-linear, evolves with and without interventions, involves trial and error in terms of intervention management, and involves many parties (actors). Controlling the process of transition as a whole is impossible, even if someone would want to (cf. Grin et al. 2010). However, there may be various forms of transition management on components, by (consortia of) governments, companies or civil societyorganizations. Transition management will usually relate to: the way actors interact with each other, coordination of sub-processes, joint fact finding, incentives, empowerment, etc.

In a transition, several phases can be analytically distinguished (fig. 1): a pre-development phase in which a variety of innovations are being developed that hardly affect the system, a take-off phase in which the system becomes unstable due to rapid and conflicting changes, creating 'windows of opportunity' for new developments to link up to the system, an acceleration phase or breakthrough phase in which physical, economic, socio-cultural and institutional changes accumulate, and a stabilization phase in which the renewed system comes to a new dynamic equilibrium. In hindsight, the direction and these stages can be recognized, but for those who are actively involved in a transition, the total picture is never clear. Actors have no more than their own perception at that moment. However, this is an analytical perspective. In reality, multiple transitions interactively evolve where it is difficult to consider a particular transition in isolation from other. ${ }^{3}$

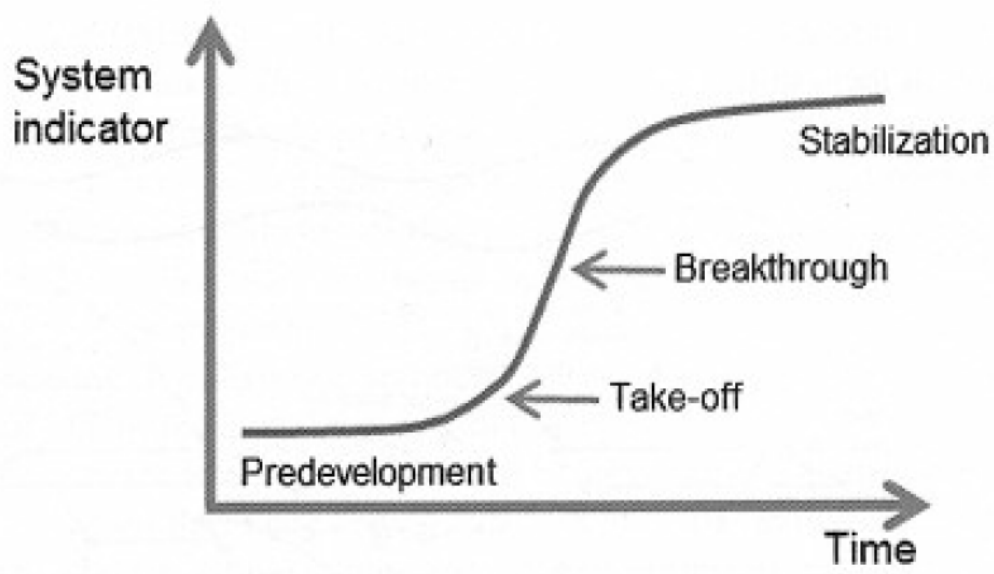

Figure 1 Phases in a Transition (Rotmans 2000).

The distinction between transition and system optimization is relevant in view of the challenges that emerge when targeting sustainable development. When confronted with the sustainability challenges in agro-food systems, most stakeholders would acknowledge that we need innovations to address these but by this they typically mean new technologies. It is increasingly recognized, however, that technical change only will not be sufficient. In this project we acknowledge this and therefore set the ambition to contribute to 'transitions' of agro-food systems, i.e. changes and innovations in which technical as well as non-technical elements of the system change, including the production and consumption side of food, as well as the governance aspects of this system.

\footnotetext{
3 We can further enrich this framework by including the destabilisation of the existing regime. Cf. Lodder, M., Roorda, C., Loorbach, D., \& Spork, C. (2017). Staat van transitie: Patronen van opbouw en afbraak in vijf domeinen. Rotterdam: DRIFT, Erasmus University Rotterdam.
} 


\subsection{Transition pathways}

The overall objective of the TransPath project is to explore 'transition pathways' towards future, (more) sustainable agro-food systems and use these to develop recommendations for various stakeholders on what they can do to stimulate the development of such sustainable systems. A 'transition pathway' is a narrative that describes how a new system may develop/evolve out of a previous system in view of a number of assumptions about how change/transition happens. Because, as was described above, a transition encompasses both technical and non-technical change, transition pathways will show the same diversity even more so because they play out in different contexts which affect related processes.

'Transition Pathway' (TP) is a general term to characterise the dynamic of transitions processes. The term can be used retrospectively, to describe past transitions, as well as prospectively, to assess possible future transitions. In the literature, a set of different TPs are distinguished depending upon differences in the niche-regime-landscape dynamic from historical transitions (Geels \& Schot 2007). In TransPath, we will use the term in the prospective sense, to explore how potential future transitions might develop.

A future transition implies that the resulting system configuration and performance (outcome) is radically different from the present system configuration and performance. From history we know that transitions, as structural system changes, can take several decades. Although we know this, we often have difficulty to understand how the world 50 or 100 years ago could have been so radically different. This 'unbelief' also plays a role in connection with the future. We find it difficult to imagine that future worlds or systems could be radically different from the present. As a result, many will consider radically different future scenarios 'unrealistic'.

The key function of exploring future transition pathways is to make such radically different scenarios 'imaginable', rather than 'unrealistic'. The main strategy to achieve this is by breaking down the future development path into incremental small steps, each of which has to be 'plausible', i.e. that most people would agree that each of these small steps would be possible. This has an 'awareness' raising effect in the sense that, if all incremental steps are plausible (or realistic), this implies that in the long term the resulting radically different new system would also become plausible. This creates openness towards addressing the question 'What can be done to stimulate the development of such radically different scenarios?', a question that would be considered irrelevant by actors who consider such scenarios 'unrealistic'.

Besides of making radically different scenarios 'imaginable', TPs will also enable a more precise dialogue among actors involved on the normative and political consequences of both the outcomes (the reconfigured system and its performance) as well as the process towards it (winners and losers along the road, governance of the transition, voices heard etc.). 


\section{Research approach}

\subsection{Introduction}

The ambition to explore transition pathways towards future, (more) sustainable agro-food systems and use these to develop recommendations for various stakeholders on what they can do to stimulate the development of such sustainable systems, implies that the overall research approach in the TransPath project needs to include the following three parts:

1. An analytical framework (AF) to analyse existing agro-food systems. This framework should specify which aspects of these systems are crucial to take into account when exploring the possibility of a future transition. The AF should also help to identify which aspects are problematic and should change to make the system more sustainable in the future and indicate which stakeholders to involve in the exploration of future TPs.

2. A transition pathway methodology to explore possibilities for the development of more sustainable future systems; this methodology should specify some 'rules' or principles for developing such pathways to make them plausible. In TransPath we seek to explore these pathways with stakeholders from the systems that are analysed.

3. A reflection methodology to reflect with stakeholders on these transition pathways to infer possibilities for intervention and strategic action. The overall objective of such interventions would be to stimulate the development of transitions towards a more sustainable agro-food system.

Each of these three parts is elaborated further in the following sections.

\subsection{Part 1: The Analytical Framework}

\subsubsection{Requirements of the AF}

The AF serves three purposes:

1. Categorization

2. First, the framework helps to identify and categorize the transitions we will study. The framework can be used as a kind of checklist for the questions and topics that have to be taken into account in the case studies.

3. General principles

4. Furthermore, the framework can help to formulate general principles for the transition of food systems. These principles do not follow directly from the framework, but the framework contributes to identify and articulate these principles.

5. Basis for practical parts

6. Thirdly, the framework can contribute to the identification of topics that require the development of new practical tools or methods.

The framework will not only be used for the case studies within the TransPath project, but also for the other projects (motifs) in the KB Food program.

Thus, the analytical framework should firstly help to map and analyse a current system. It should do so in a dynamic way, showing how change of the system has taken place to be able to identify plausible future changes in the second part (exploration of transition pathways).

Concerning this dynamic, the analysis of past transitions shows that systems tend to resist change, leading to evolutionary patterns of successive gradual changes, characterised by path dependency. Path dependence theory was originally developed by economists to explain technology adoption 
processes and industry evolution. The theoretical ideas have had a strong influence on evolutionary economics (Nelson and Winter 1982).

However, while systems create barriers for change, there are always actors active at the 'fringes' of a system, trying to change things by working on 'novelties'. Novelties can also be called innovations, provided that innovation is taken as a socio-technical phenomenon in accordance with the sociotechnical nature of systems. The study of past transitions shows that their origins can often be traced back to such novelties or innovations that were initially not taken seriously, at least not by the main stakeholders in the system.

The dynamic of a transition can then be seen as a dialectic process between on the one hand forces that create barriers for change and on the other hand small groups working on novelties that seek to link up to the system and try to change it. Our analytical framework should then allow us to account for that kind of dynamic. Furthermore, the exploration of future transition pathways should also be based on the same type of dynamic.

On the basis of the discussion above and the ambitions of the TransPath project we can specify the following general requirements for the analytical framework that will be used:

1. It should build on all aspects of systems (social, technical, ecological);

2. It should help identify the main characteristics of these systems, the technical as well as the nontechnical aspects (including consumption and use, governance);

3. It should help understand the dynamic of change in these systems;

4. It should allow a macro perspective to be able to see the 'general pattern' of a transition;

5. At the same time, it should also allow focusing in to the micro level of 'novelties', their dynamic and how they may link up to the existing system;

6. It should pay attention to normative aspects, including sustainable development;

7. It should allow identifying barriers for change as well as 'opportunities' that may facilitate the linking up and further penetration of novelties.

Especially requirement 4 and 5 may appear problematic as they seem to be contradictory. Analytical perspectives or theories typically either focus on the macro or the micro level, but not both. We will address this problem by choosing an 'overall perspective', notably the so-called multi-level perspective $(M L P)$ on transitions, that focuses on the macro level and additionally specify a number of 'zooming in' approaches that build on other theoretical perspectives. We will discuss the MLP and the 'zooming in' approaches in two separate sub-sections below.

\subsubsection{MLP: The macro dynamic of transitions}

To study the overall pattern of transition processes we adopt the Multi-Level Perspective (MLP) that approaches radical socio-technical innovations (transitions) as an interplay between three levels: sociotechnical niches, a socio-technical regime and the socio-technical landscape. The concept of anchoring is used to analyse in detail how niches may initially link up to regimes (the 'take-off' phase in fig. 1 above) and the concept of scaling describes the wider uptake of innovations by the regime (the 'breakthrough' phase). The Multi-Level Perspective is developed to understand socio-technical innovations, but has a wider scope, while every transition includes an interplay between experiments in niches, a dynamic system (regime) of rules and customs, and a general context. This implies that also social innovations can also be analysed using the Multi-Level Perspective.

In the MLP, a system (like the agro-food system) would be called the regime. In the MLP dynamic, system innovations or transitions develop as follows (cf. fig. 2 below). Initially, the regime (or system) changes little and innovations are of an incremental nature. At the same time, novelties (alternatives to regime practices) are developed in local practices and become part of a niche when a network of actors is formed who share certain expectations about the future success of the novelty, and who are willing to fund and work on further development. Niches may emerge and develop partly in response to pressure and persistent problems in an existing regime which can be either internal to the regime itself (e.g. plant pests in agriculture) or come from the socio-technical landscape (e.g. the pressure to curb $\mathrm{CO}_{2}$ emissions which affects more than just agriculture). 


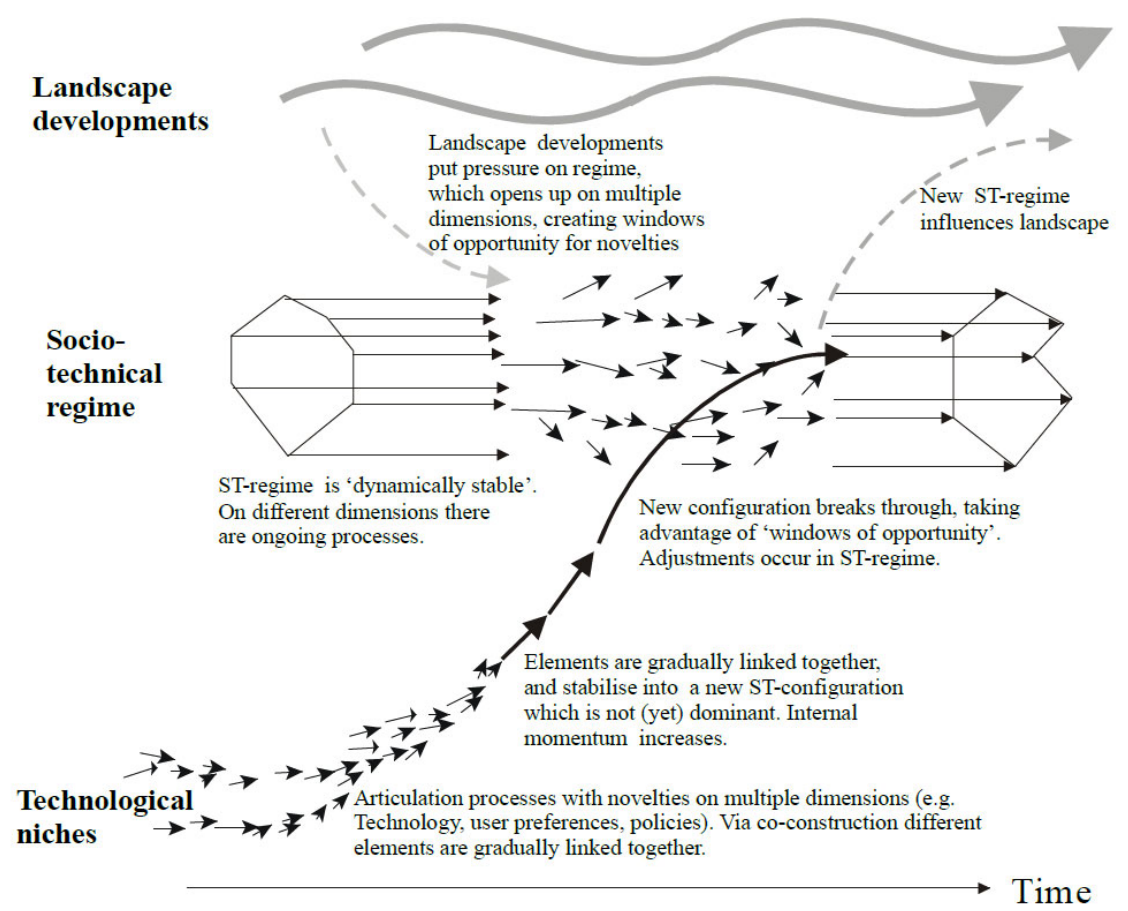

Figure 2 A dynamic multi-level perspective on system innovation (Geels 2005).

The further success of niche formation is on the one hand linked to processes within the niche (microlevel) and on the other hand to developments at the level of the existing regime (meso-level) and the socio-technical landscape (macro-level). Supported by actors willing to invest in the new concept (industries, R\&D organisations, government) and initially protected from competition at the market place (e.g. through subsidies), the novelty is improved within the niche, broader networks are formed around it, and more is learned about directions for improvement and functions it may fulfil.

Anchoring: Linking niche and regime. To study the initial uptake of innovations by the regime, the concept of anchoring is used, which was developed in the context of system innovation programmes in the Netherlands (Loeber 2003, Grin \& Van Staveren 2007). In a study of the uptake of radical energy novelties in glasshouse horticulture, the concept was defined more specifically as follows: "Anchoring is the process in which a novelty becomes newly connected, connected in a new way, or connected more firmly to a niche or a regime. The further the process of anchoring progresses, meaning that more new connections supporting the novelty develop, the larger the chances are that anchoring will eventually develop into durable links." (Elzen et al., 2012, p.3)

Next to the three levels, the MLP distinguishes three general dimensions to characterise a regime (or system) and a niche, viz. (Geels, 2004):

- T: Technologies (components, devices, infrastructures);

- $\mathrm{N}$ : Networks and actors (individuals + organisations) and the roles they play;

- I: Institutions (rules, both formal (including regulation) and informal rules).

Building on this distinction between three constituent components of a regime, Elzen et al. (2012) distinguish three forms of anchoring. These are technological anchoring, network anchoring and institutional anchoring. Technological anchoring takes place when the technical characteristics of a novelty (e.g. new technical concepts) become defined by the actors involved and, hence, become more specific to them. Network anchoring means that the network of actors that support the novelty changes, e.g. by enrolling new producers, users or developers. Institutional anchoring relates to the institutional characteristics of the novelty, i.e. the new rules that govern its further development and uptake. Institutional anchoring implies that developments within a niche or regime become translated into adapted or new rules that govern, at least temporarily, the activities of both niche and regime actors. 
For the agro-food domain, the three main dimensions can be further refined to include, for instance, the various dimensions that are distinguished in the Food System Model (FSM) by Van Berkum et al. (2018). This will be addressed in the next sub-section on 'zooming in'.

In the MLP, transitions are analysed as an interplay between the three levels and the development of these three dimensions ( $T, N, I)$. What distinguishes transitions from 'innovation' is that in the latter there is a lot of change on the technological dimension but relatively little on the networks and institutional dimensions. In transitions, all three dimensions change by influencing each other (called a 'leapfrog dynamic').

\subsubsection{Zooming in: analysing micro-level dynamics in transitions}

In its crudest form, the MLP distinguishes three dimensions, viz. technology, networks and institutions. This helps to obtain an overall systemic view of a transition process but it provides little insight into the acts of single actors and the effects this has on the transition process. Since the TransPath projects seeks to develop lessons also for various types of stakeholders, this implies a need to be able to zoom in to the level of individual actors. Based on the project's objectives we can set the following requirements for this zooming in:

- Address market dynamics and economics;

- Address ecological conditions;

- Address legislation and governance in the broad sense;

- Address linking between niches and system/regime (anchoring);

- Address the role of normativity, including sustainable development (build on RRI).

In the literature, several of these requirements are explicitly addressed, e.g. in the Van Berkum et al. (2018) agro-food system model. We can use these requirements to enrich the MLP by categorising these as sub-dimensions of the three main dimensions or possibly change these.

Van Berkum et al. have developed the 'Food System model' (FSM; fig.3). The FSM views the behaviour of a system as an interplay of interacting subsystems, in which feedback plays a key role, rather than as a simple chain of cause-effect relationships.

Whereas MLP only uses three general concepts to characterise a regime (technology, actors and institutions), FSM uses a much more refined set. Since a regime in the sense of MLP can be seen as a system in the FSM sense, we will use the FSM to 'enrich' the regime analysis using MLP. The main reason to emphasise the use of MLP is its attention for the development of niches that can serve as the 'trigger' for transitions and this type of dynamic is not conceptualised in the FSM.

The FSM looks at the interactions within the food system and its socio-economic and biophysical environment. It also highlights policy pathways that do not intervene in the value chain itself, but in the context of the food production system.

The FSM Distinguishes four sets of concepts:

- Food system activities.

Food system activities consist of five components: the food supply system (the value chain), the enabling environment, business services, the food environment and consumer characteristics.

- Socio-economic drivers (distinguishing markets, policy, science \& technology, social organisation, individual factors);

- Environmental drivers (distinguishing soil, fossil fuels, minerals, biodiversity, water);

- Food system outcomes (distinguishing food security (combination of food utilisation, food access and food availability; FAO definition in Box 1), socio-economic outcomes \& environmental outcomes). 


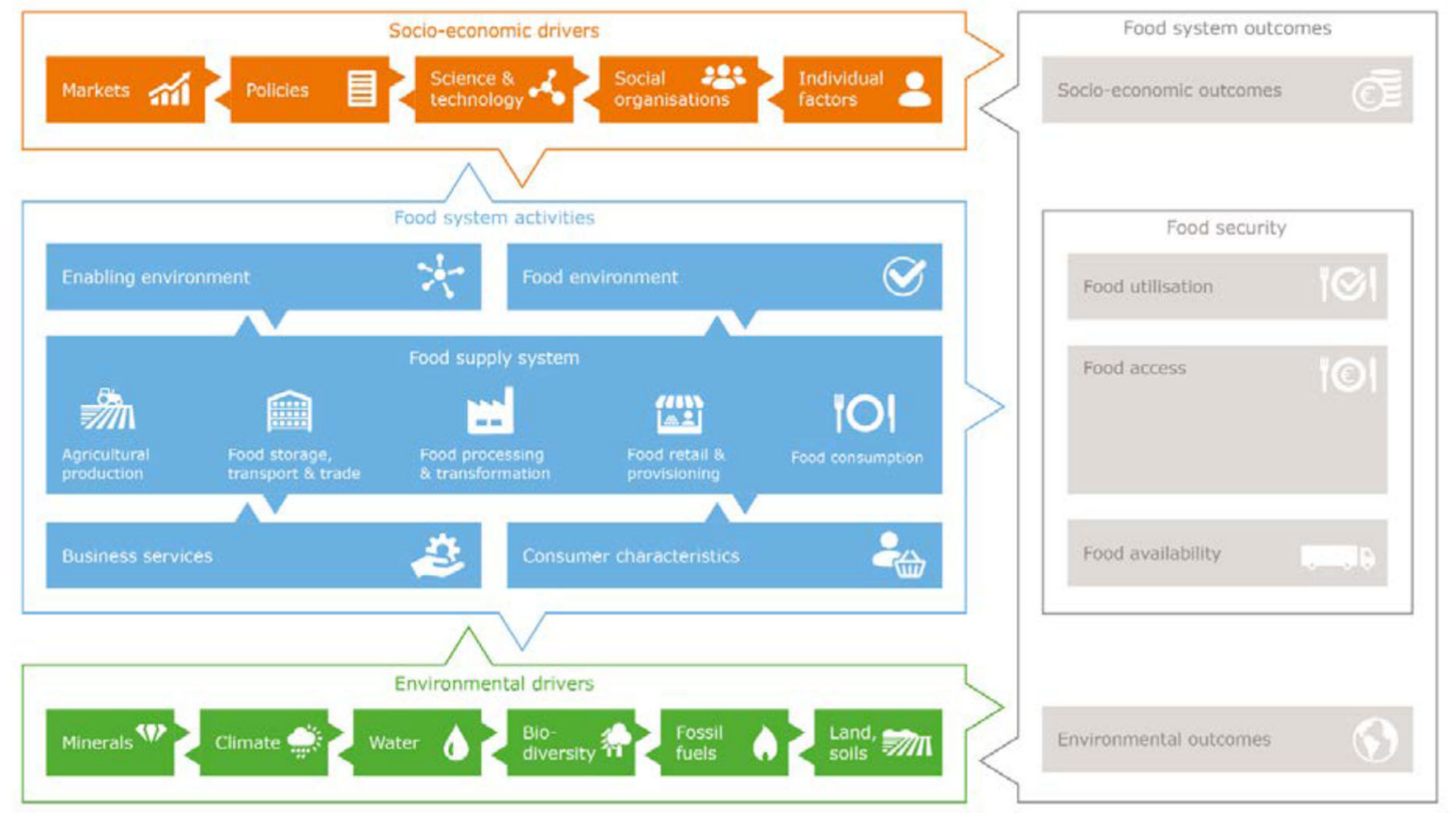

Figure 3 A way of mapping the relationships of the food system to its drivers (Van Berkum et al. 2018).

Next to the FSM, there are other relevant approaches like the the 'Food System Regimes' approach (FSR; Gaitán et al., 2019) that is depicted in Figure 4.

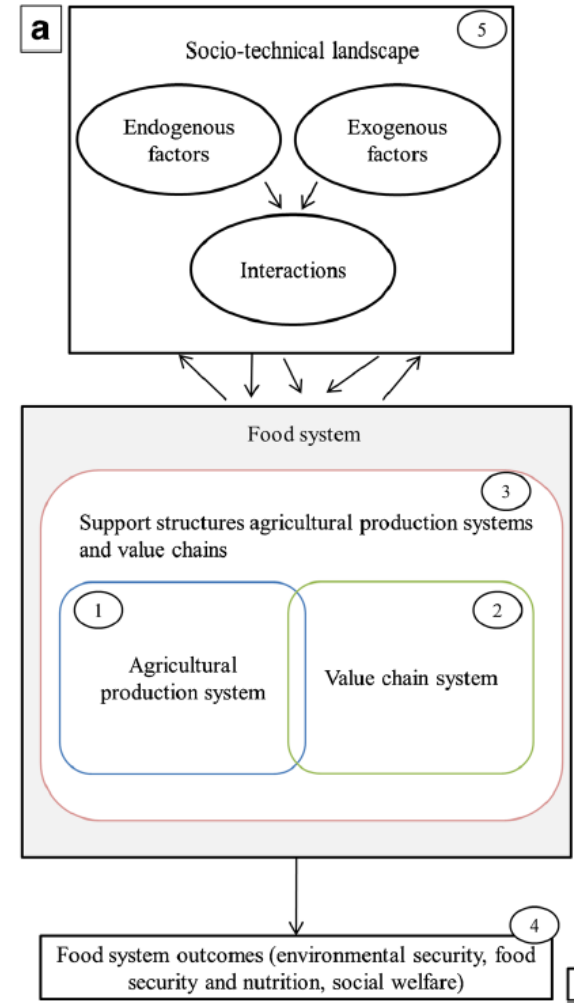

Fig. 3 The food system. a Components of a food system: agricultural production system (number 1), value chain system (number 2), and structures for support of innovation and everyday functioning of agricultural production systems and value chains (number 3 ) and food system outcomes (number 4). The three components influence and are influenced individually or jointly by the socio-technical landscape (number 5). The conceptualized food system builds on Ericksen's

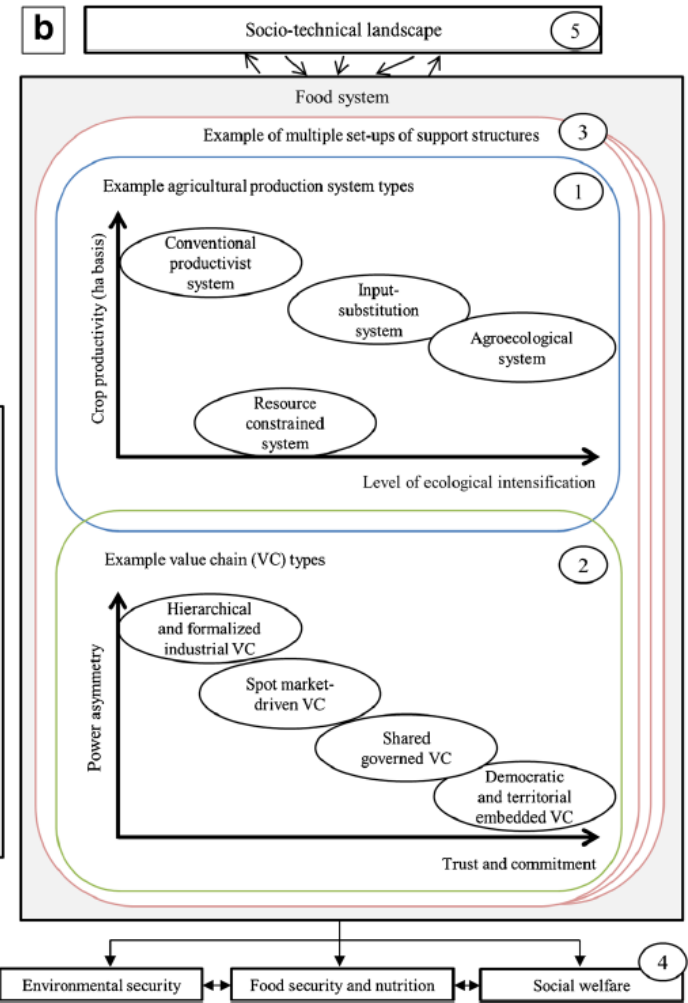

(2008) food system framework. b Heterogeneity within the three components of the food system. Illustration of the possible diversity of agricultural production systems (number 1) and diversity of value chains (VC) (number 2), which are embedded in multiple setups of structures for support of innovation and everyday functioning of agricultural production systems and value chains (number 3 )

Figure 4 Food System Regimes (Gaitán et al., 2019). 
A further enrichment of the MLP with actor perspectives can be based on Rauschmayer et al. (2015) who link transition management capabilities with social practices. They stress that "Societally relevant research on and for sustainability transitions ... has to produce systems, target, as well as transformative knowledge. The challenges of sustainability transitions require furthermore that the individual and the societal levels have to be linked as to relate individual agency and structural change within the different knowledge types." To achieve this, these authors propose to combine transition management approaches with the more descriptive practice theory and the more normative and individualistic capability approach (see Figure 5).

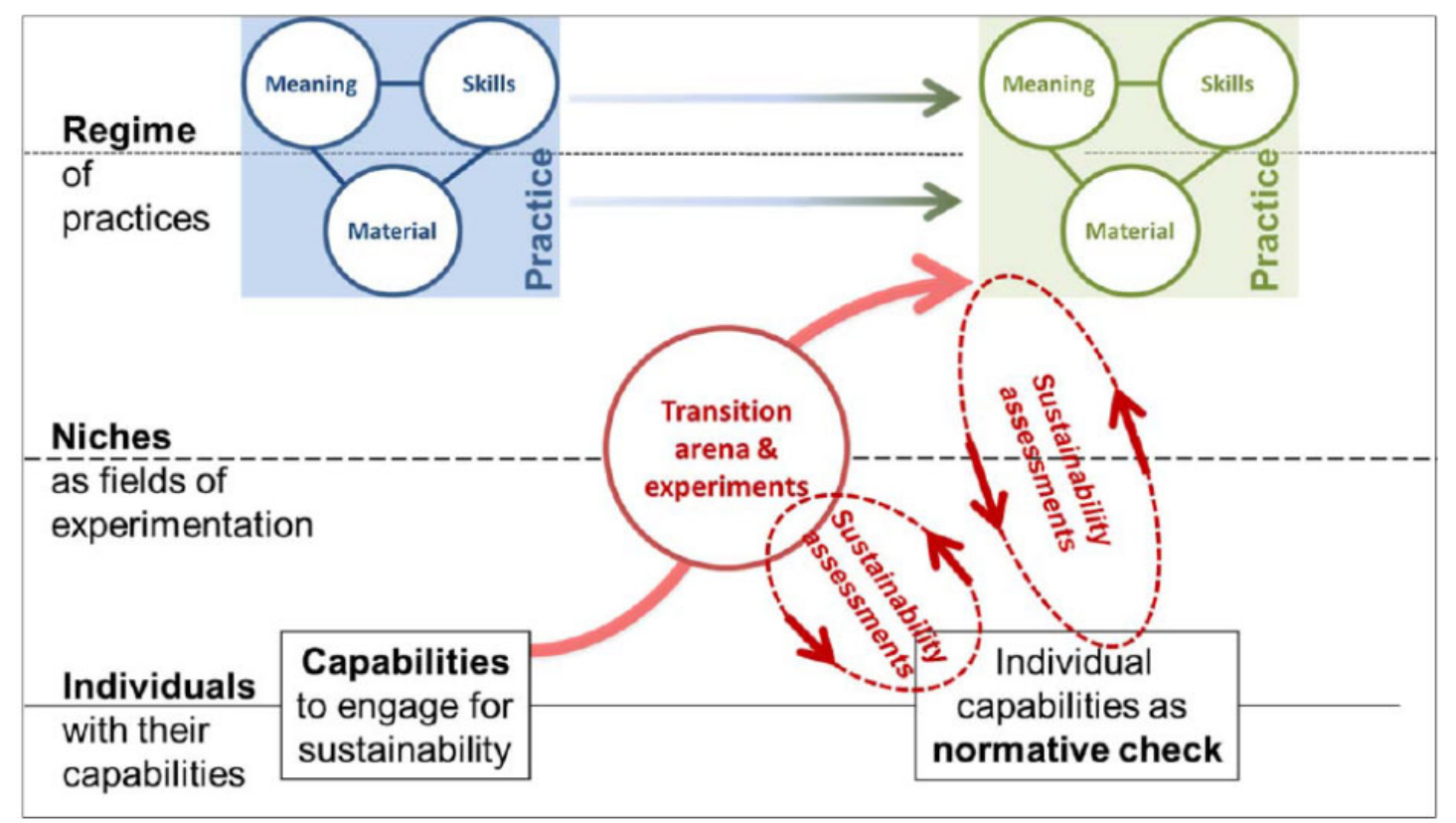

Figure 5 Assembling practice theory, transition management and capability approach for governing sustainability transitions (Rauschmeyer et al. 2015).

To assess the potential relevance of these model to enrich the MLP with agency perspectives, the following observations may be important:

- FSM only sees one 'agro-food system'. FSR is a bit more specific by specifying 3 food system 'components', that may also be seen as 'subsystems', viz:

- agricultural production system;

- value chain;

- structures for support of innovation and everyday functioning.

- This distinction seems useful for our project because these three components (or subsystems) are largely separate in terms of actors, technologies and institutions (the three main dimensions from MLP);

- FSR talks of 'systems' in plural; FSM sees one big system. This makes it possible for FSR to look at the dynamic between an 'incumbent system' and potential alternatives that are developed in an 'alternative system'. FSM does not provide any tools for this yet (although these are being developed by WECR and WCDI in 2020, including a political economy lens for analysing food systems).

- Distinguishing between 'incumbents' and 'contenders' in alternative systems seems essential to be able to analyse the role of power, i.e. both how it resists change as well as how forms of power may be overcome.

We still need to discuss further what these models imply, what they contribute to further insight in the process of transition (i.e. pathways) and how we will use these to define our analytical framework. In 2020, the 'enrichment' of the MLP on the basis of FSM and FSR will be further elaborated. This will require a further assessment of what these models imply, what they contribute to further insight in the process of transition (i.e. pathways) and how we will use these to define our analytical framework. This elaboration reflects a number of different perspectives on the analysis of transitions that are 
presented in Annexes 1 and 2. In further work we will seek to integrate this into a single coherent approach.

\subsubsection{Operationalising sustainability}

The general approach is that we will not look at agriculture in the narrow sense but at broader 'agrofood systems' in which agriculture is part of a wider system in which a variety of actors play various roles and have various motivations and interests. Several models are developed to describe the agrofood system in its environment. Two examples are mentioned in the previous paragraph.

The motivation for the project is that many of these systems presently are not sustainable $\mathrm{e}^{4}$ by creating a variety of problems. Here sustainability is taken in the broad sense as 'integral sustainability', i.e. sustainable on a broad variety of dimensions. In this most general sense this includes the three Ps, i.e. (all) people, (the whole) planet, (responsible) profit. This means that it is socially, environmentally and economically sustainable as expressed in the UN's set of 17 Sustainable Development Goals (SDGs). One dimension of sustainability addresses ecology. Annex 2 describes four different aspects of ecology that will be taken into account.

It is increasingly acknowledged that this 'integral sustainability' cannot be achieved by a mere technical change of present agro-food systems but that more radical changes are needed, called system innovations or (sustainability) transitions (see above discussion).

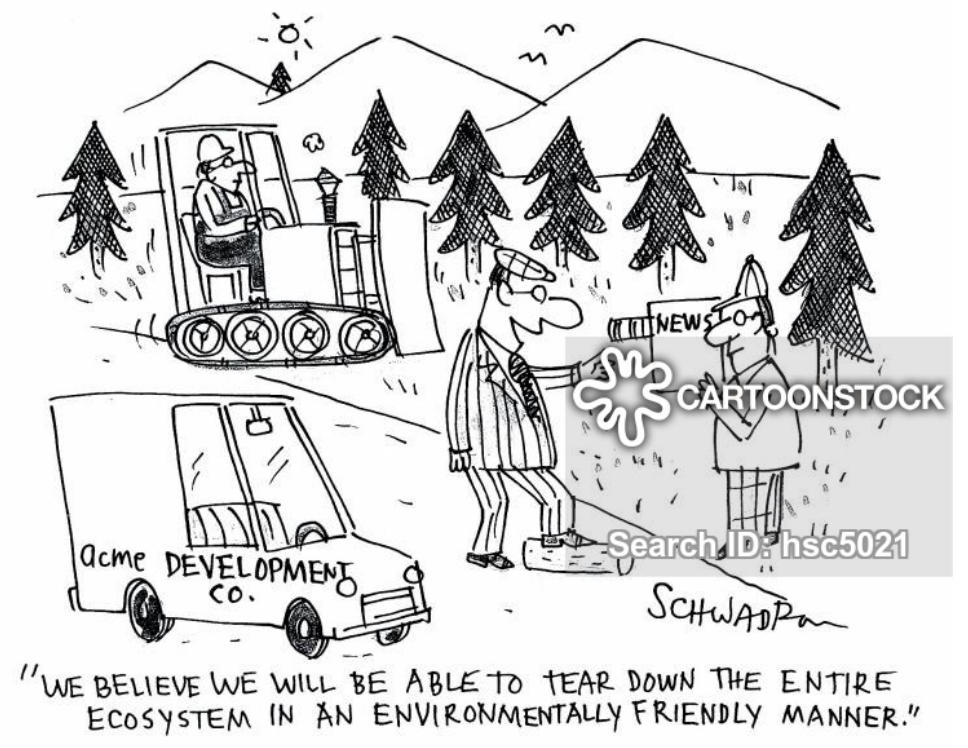

\subsubsection{Operationalisation for case study work}

In the period 2020-23, the approach described above will be used to analyse and support the other motifs (projects) in the KB Food programme. In 2019, the first draft of this approach has been applied to a set of 'quick cases' to test its practical applicability and to develop it further. To this end, the approach was operationalised into a set of 'guidelines for quick cases' that describe how to analyse and describe the cases. These are presented in Annex 4. In 2020, these will be further refined and 'tailored' for application in the various motifs.

\footnotetext{
${ }^{4}$ The term "sustainability" by itself does not provide a sufficiently clear description of visions. It is therefore important to unpack it and to consider its implications in relation to different spheres of life, such as social sustainability, economic sustainability, ecological sustainability. This requires an integral perspective on sustainability, also in view of potential trade-offs between different types of sustainability, or sustainability at different scale levels. This involves fundamental questions about what may be considered 'sustainable', e.g., can unsustainable practice in one place be compensated by sustainable practice in another place after which the entire system can be labelled as 'sustainable'?
} 


\subsection{Part 2: Exploring transition pathways}

\subsubsection{Focus on development process rather than outcomes}

The analysis of the developments in the various KB motifs and the involvement of stakeholders seeks to develop a set of recommendations for these stakeholders on how to better realise their sustainability objectives. The next step is to assess the practical value of such recommendations and to ensure that they will have impact. In this respect, TransPath will take a step further than is common in research projects by doing this in the form of an exploration of possible future 'transition pathways'. TransPath acknowledges that achieving impact can be problematic and will make an effort to explore how and under which circumstances this impact may be achieved and how this impact may be increased through strategic action by various stakeholders. This requires some sort of foresight methodology to explore what might happen in the future.

To avoid misunderstanding: in contrast to the common belief, foresight exercises are not intended to predict the future. They are an attempt to explore possible futures to try and better understand what might happen under different circumstances. The main function of using such an approach in TransPath is 'awareness raising' that certain forms of change towards sustainable agriculture are possible and to explore the potential of specific forms of 'strategic action' by different stakeholders (including public authorities) to stimulate this to happen.

Transition pathways follow very crooked courses, including a leapfrogging of technical and social change. Hence, exploring potential future courses can easily 'go all over the place'. To get some sense of direction, it is necessary to first define a 'future target' that the pathway will lead to, i.e. a vision of a future agro-food system that is (seen as) sustainable. To contribute to sustainable development, this vision of the future should be such that present sustainability problems no longer exist in that vision, which probably implies a 'radically different' future.

There are various ways to develop such future visions and in the various KB motifs we will try out some of these in workshops, together with stakeholders. These methods have not only a substantive purpose, but also function to empower stakeholders and to create more equality between stakeholders in the discussions on the future.

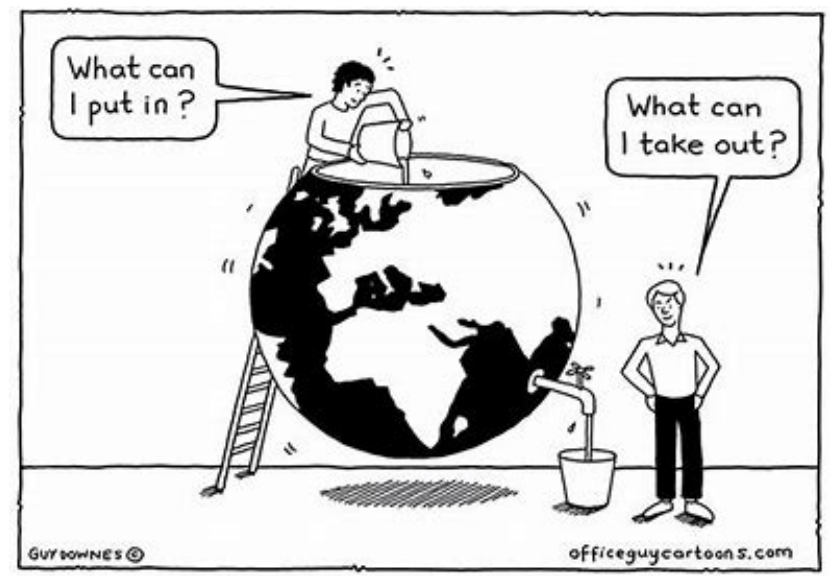

To explore future transition pathways we can build on a backcasting scenario method called 'SocioTechnical Scenarios' (STSc; Hofman and Elzen 2010). This method builds on the MLP and specifies a number of characteristic 'patterns' and 'mechanisms' based on the multi-level dynamic that can be used as 'building blocks' to construct plausible future pathways. The main result of the exercise is not the future target but the pathways that may lead to such futures so differences of opinion on 'desirability' may be resolved by using some simple means to cut knots on the future targets. The STSc method differs from various other scenario methods in two ways:

- Other scenario methods typically take the existing social order as given and explore how new technologies may be adopted in the future within that social order. Thus, there is much change on the technical dimension from the MLP but little or none on the network and institutional dimensions. 
In an STSc, however, following the dynamic of the MLP, not only the technical may change but also the societal and institutional.

- The outcome of a traditional scenario is a 'state of affairs' at some point in the future. This future follows from applying a limited set of rules, sometimes in the form of an algorithm that runs on a computer. The STSc starts by developing a set of possible 'visions of the future' and then reasons backward (a form of backcasting; Vergragt and Quist 2011) how this future may develop from the present. This then renders a transition pathway as the outcome of the scenario.

\subsubsection{Application in TP workshops}

The STSc method can be applied in two ways:

- In an 'expert mode': by a researcher or group of researchers

- In an 'interactive mode': by a group of stakeholders, facilitated by a researcher.

In this project we will use the second application. This means that we will follow the steps below, some of which are research tasks while others are carried out in interaction with stakeholders.

The first two tasks are carried out by researchers:

1. Analysing the existing system in terms of the 3 MLP dimensions $(T, N, I)$. This implies the characterisation of all three MLP levels: regime, niches, landscape. This analysis can be made more specific by using a more refined approach to analyse a system like the Food System Model (FSM; van Berkum et al.).

2. Assessment of sustainability challenges. Analyse what the important opportunities and barriers are to tackle these challenges, based on new developments in niches, the main dynamic in the regime and the pressure(s) that emerge from the socio-technical landscape.

All further tasks below are carried out with stakeholders:

1. Presentation by researchers to stakeholders of the main findings of the first two steps.

2. With stakeholders, develop a 'sustainable vision of the future' (one or more) in which the sustainability challenges have been addressed adequately.

3. Characterise this vision of the future in terms of the three MLP dimensions: technology, networks, institutions (to be more refined using the FSM).

4. Set targets for the three dimensions $(T, N, I)$ for the reference years of the scenario such that the changes from one episode to the next appear plausible within the timeframe of an episode (e.g. a decade).

5. Construct a narrative how one episode may develop out of the previous episode by making use of the multi-level dynamic from the MLP and a number of characteristic 'mechanisms' and 'patterns' from the MLP literature. This narrative describes the targeted 'sustainable transition pathway'.

6. Reflection: Assess the scenario in strategic terms. What role do various actors play? How can they make the pathway more 'robust'? Translate this into recommendations for various stakeholders (including policy-makers). This is elaborated in 'Part 3 ' of the research approach below.

\subsection{Part 3: Reflection methodology}

The analytical approach provides a way of understanding specific food system configurations in context and of exploring possible transitions to different configurations because of their more desirable outcomes. Strategizing in relation to such transitions involves considering different preferred transition processes, and in relation to those: different (stakeholder) perspectives, different options and opportunities, different requirements for engaging (through interventions), and different wider implications, including possible trade-offs, etc.

This implies that a process of analysing needs to be followed, or rather complemented, by a scoping and sense-making process to assess options in a broader sense that supports not only strategic decision-making, but also reaching agreement as partners on preferred options and implied needs and roles to play. 


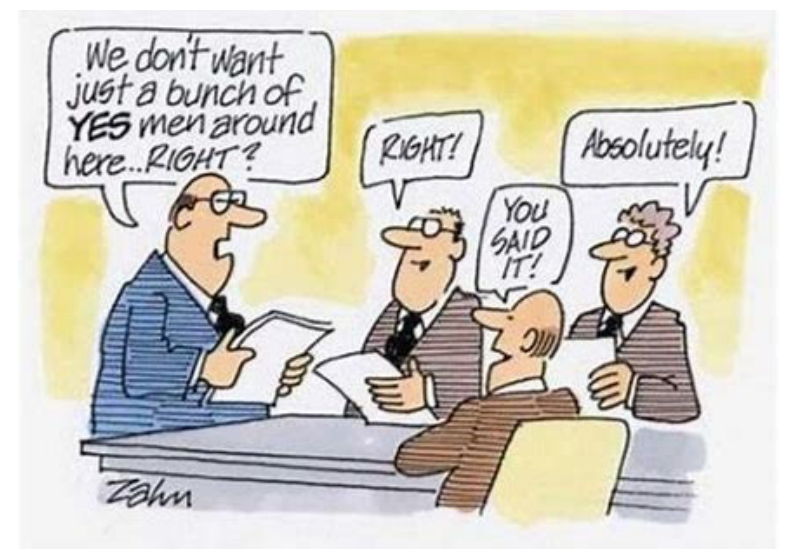

A related methodology will be further elaborated later in the project, Making use of tools which already have been tested or will be tested or developed. These include:

- 'Strategic Scoping': https://www.preprints.org/manuscript/201911.0386/v1 (developed in collaboration with the KB Feeding Cities motif).

- 'Transition Support System' approach (Dijkshoorn, 2018): applied in different projects:

- https://www.wur.nl/en/article/Working-together-towards-sustainable-food-system-inOverijssel-the-Netherlands.htm (https://edepot.wur.nl/510250);

https://www.wur.nl/en/Research-Results/Research-Institutes/Economic-

Research/Research-topics-WEcR/Nourishing-the-world/Transition-Support-Systemapproach.htm

https://www.wur.nl/en/article/Food-security-in-the-future-challenges-for-AccraGhana.htm (https://library.wur.nl/WebQuery/wurpubs/fulltext/476203) 


\section{References}

Berkum, S. van, Dengerink, J., and Ruben, R (2018.) The food systems approach: sustainable solutions for a sufficient supply of healthy food. Wageningen, Wageningen Economic Research, Memorandum 2018-064. https://library.wur.nl/WebQuery/wurpubs/fulltext/451505

Dijkshoorn-Dekker, M. Transition Support System approach; Wageningen Economic Research: The Hague, The Netherlands, 2018; p. 3;

Elzen, Boelie, Cees Leeuwis and Barbara van Mierlo, 2012. "Anchoring of Innovations: Assessing Dutch efforts to harvest energy from glasshouses". Environmental Innovation and Societal Transitions, 5, pp.1-18.

Elzen, Boelie, Frank W. Geels and Ken Green (eds.). System Innovation and the Transition to Sustainability, Cheltenham: Edward Elgar Publishing Ltd. (2004).

Gaitán-Cremaschi, D., Klerkx, L., Duncan, J., Trienekens, J., Huenchuleo, C., Dogliotti, S., Contesse, M. Rossing, W. (2019). Characterizing diversity of food systems in view of sustainability transitions. A review. Agronomy for Sustainable Development 39(1) 10.1007/s13593-018-0550-2

Geels, F. W. 2004. From sectoral systems of innovation to socio-technical systems; Insight about dynamics and change form sociology and institutional theory. Research Policy, 33, 897-920.

Geels, F.W. and Schot, J. 2007. Typology of sociotechnical transition pathways. Research Policy, Vol.36, pp. 399-417.

Geels, F.W., 2005. Technological Transitions and System Innovations: A co-evolutionary and sociotechnical analysis. Edward Elgar Publishing Ltd., Cheltenham.

Grin, J., van Staveren, A., 2007. Werken aan Systeeminnovaties (Working on System Innovations). Van Gorcum, Assen.

Grin, John, Jan Rotmans and Johan Schot, 2010. Transitions to Sustainable Development. New Directions in the Study of Long Term Transformative Change. New York: Routledge.

Hall, A. and Dijkman, J. 2019. Public Agricultural Research in an Era of Transformation: The Challenge of Agri-Food System Innovation. Rome and Canberra: CGIAR Independent Science and Partnership Council (ISPC) Secretariat and Commonwealth Scientific and Industrial Research Organisation (CSIRO).

Hofman, Peter S., and Boelie Elzen, 2010. Exploring System Innovation in the Electricity System through Sociotechnical Scenarios. Technology Analysis and Strategic Management. Vol.22, No.6, pp.653-670.

Loeber, A., 2003. Inbreken in het gangbare: Transitiemanagement in de praktijk - De NIDO benadering (Breaking in into the Usual: Transition Management in Practice - The NIDO Approach). NIDO, Leeuwarden.

Nelson, R, and S. Winter (1982). An evolutionary theory of economic change. Harvard University Press.

Rauschmayer, Felix, Bauler, Tom and Schäpke, Niko, 2015. Towards a thick understanding of sustainability transitions - Linking transition management, capabilities and social practices. Ecological Economics 109. Pp 211-221.

Spaargaren, Gert, Anne Loeber, and Peter Oosterveer (eds.), 2011. Food Practices in Transition. New York: Routledge.

Sutherland, L-A., Darnhofer, I., Wilson, G.A. and Zagata, L. (eds) 2014. Transition Pathways towards Sustainability in Agriculture: Case Studies from Europe. Wallingford: CABI.

Vergragt, Philip J. and Quist, Jaco 2011. Backcasting for sustainability: Introduction to the special issue. Technological Forecasting \& Social Change, 78 (2011) 747-755

Wigboldus, Seerp, Laurens Klerkx, Cees Leeuwis, Marc Schut, Sander Muilerman and Henk Jochemsen, 2016. Systemic perspectives on scaling agricultural innovations. A review. Agron. Sustain. Dev., 36:46, 1-20. 


\section{Annex 1 Perspectives on Transitions}

The following may be considered as providing assessment angles on the way in which relevant cases engage with the (ambition for) food system transition. It can be used to develop a reflection methodology as mentioned in Ch.3.

The diagram presents a MLP perspective with five specified angles on what is both part and parcel of MLP and what is not addressed through it, but for which it does provide a useful framework to organise perspectives on (food system) transition processes.

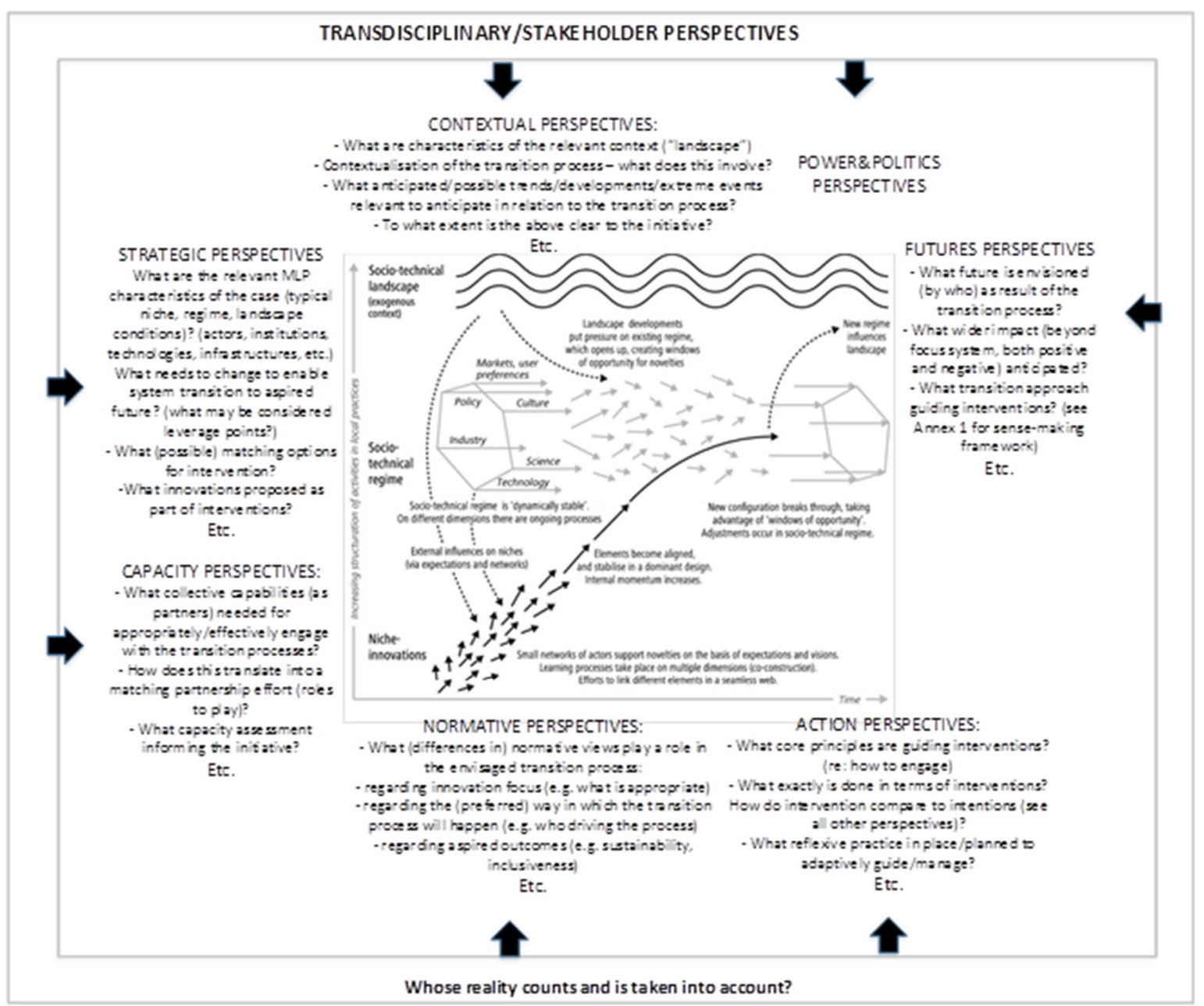

Related questions regarding tools and methods used in relation to this (e.g. as lead actor in interventions):

Strategic perspectives, e.g.:

- Use of theories, models and other tools to create a (food) systems perspective

- Methods for assessment of what shapes system (MLP) configurations

- Methods for assessing readiness of innovations to go to scale (become part of regime)

- Methods to translate wider analysis

Contextual perspectives, e.g.:

- Methods for context analysis

- Methods for futures search/scenario exploration

- Methods for risk analysis 
Futures perspectives, e.g.:

- Methods for visioning (particularly involving a participatory approach)

- Methods which help explore transitions and anticipated impact in a holistic/integral way

- Methods which help to explore paradigms, approaches, etc. regarding transition orientations

Normative perspectives, e.g.:

- Methods to guide perspectives on responsible innovation dimensions/principles

- Methods for creating appropriate evaluative (monitoring) frameworks and approaches

- Methods for clarifying normative orientations such as what is meant by sustainability, resilience, etc.

- Multi-stakeholder facilitation methods to explore differences in normative perspectives on what is relevant in relation to the envisaged transition

Action perspectives, e.g.:

- Methods to translate situation analysis into capacity needs

- Methods to assess (collective) capacity/capabilities of stakeholders/(potential) partners

- Multistakeholder methods to form partnerships and guide/support those as they involve 


\section{Annex 2 Socio-Ecological Transistions and the Multi level Perspective}

\section{Ecology in transitions}

The Multi Level Perspective is aimed at the conceptual modelling of the dynamics of innovation processes. In the general description of the MLP the role of water, soil, climate and biodiversity, here summarized as ecology, is missing. This paragraph describes an extension of the MLP which includes the role of the ecology.

In general, ecology can relate to the following aspects of transition processes:

1. Ecology as condition for human activities.

- As a boundary condition for human actions

- As capital, delivering (or being unable to deliver) ecosystem services.

2. Ecology as integral part of socio-ecological practices.

3. Ecology as discourse: a way of speaking and thinking about the natural environment, including normative ideas on human behaviour.

4. Ecology as one of the domains in which transitions take place.

\section{Enriching the MLP}

Ecology as capital could be seen as element of the landscape level. The landscape level, which in the MLP is just a metaphor for contextual development, can be broadened with an ecological component. This choice also has consequences for the relationships between the landscape level and the regime level. The landscape level is then not just a condition, but can also be an enabler for regime developments.

Ecology as part of socio-economic practices is aspect of the regime level. We have two options: describing ecology as actor, like Bruno Latour, or consider the routines in socio-ecological systems as part of what in the MLP is called technologies, which then includes all practices using the ecosystem.

Ecology as discourse. Theories, concepts, ideas and norms on the ecology are leading in debates within the regime level, especially in the institutional layer of the regime level.

Ecology as transition domain. Seen from the MLP this is a specific interaction between the niche, regime and landscape level aimed at new ways to deal with the physical and natural environment. 


\section{Landscape thrileponests}

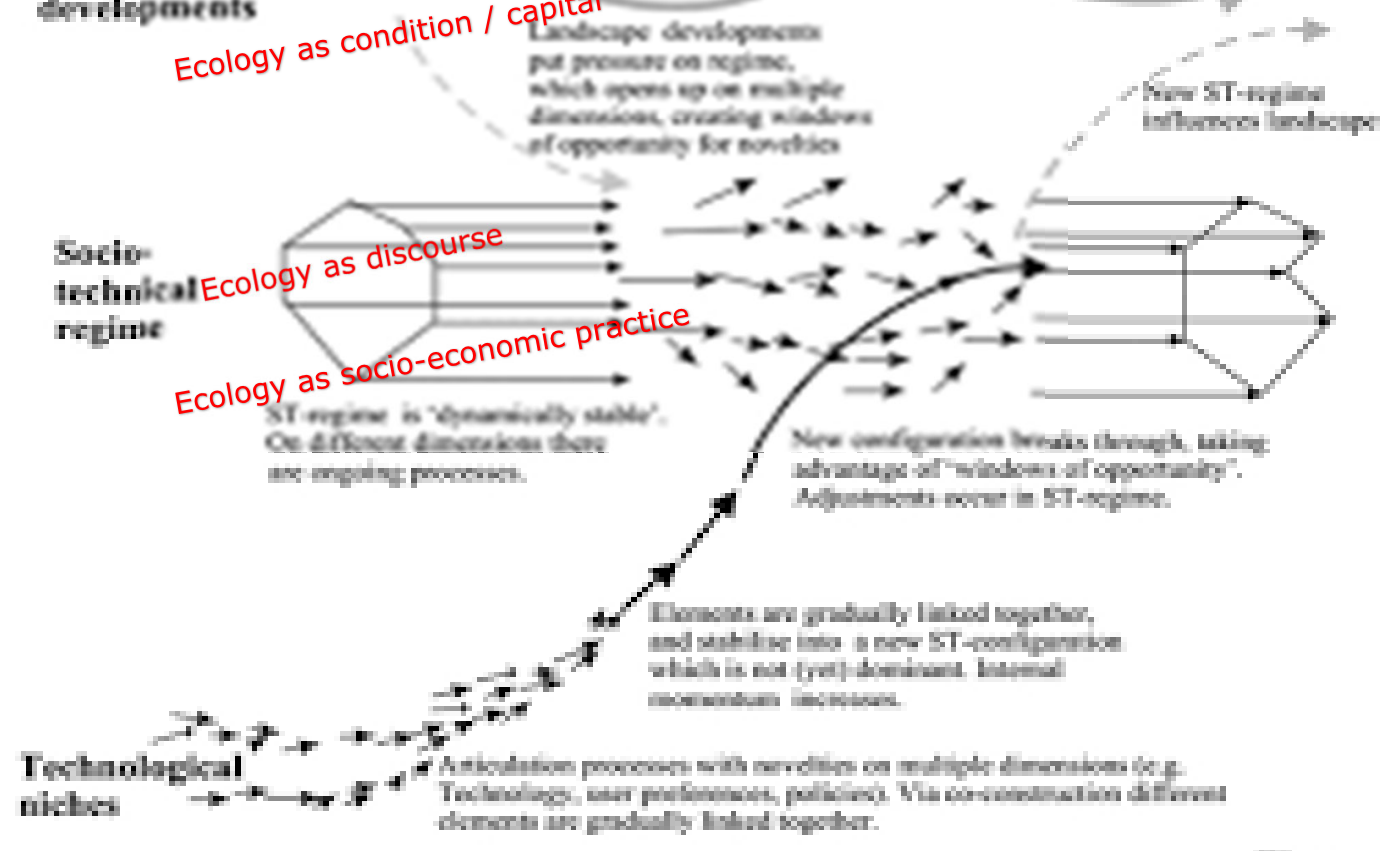




\section{Annex 3 Guidelines for 'quick cases'}

\section{Introduction}

This memo explains how to use the template for the description of cases of a transition or transition pathway in the food system.

The first three sections provide a description of the history and the present configuration of the (food) system of your case. The final two sections assess potential changes to make it more sustainable.

For each section we give a suggestion for how long it could be to give you an impression of how detailed your discussion should be. The total is 4 pages which indicates an average, so your case report should be app. 3-5 p long.

You will find the five sections of the report in a separate template and the expected content for each of these sections is explained below.

\section{Case study selection}

- Lifespan of the project (at least a few years in implementation phase, preferably gone through a project cycle for at least once so that lessons for evaluation were taken into a next phase)

- Preferably projects in Low and Middle Income Countries (LIMC)

- Projects/programmes explicitly aiming for systems change, transitions, transformations

\section{Main case characteristics and history (0,5 page)}

Describe the case in your own words in 5-10 sentences. Also address the main sustainability (or SDG) challenges in the case.

What is the place of the case study in the food system, see graph?

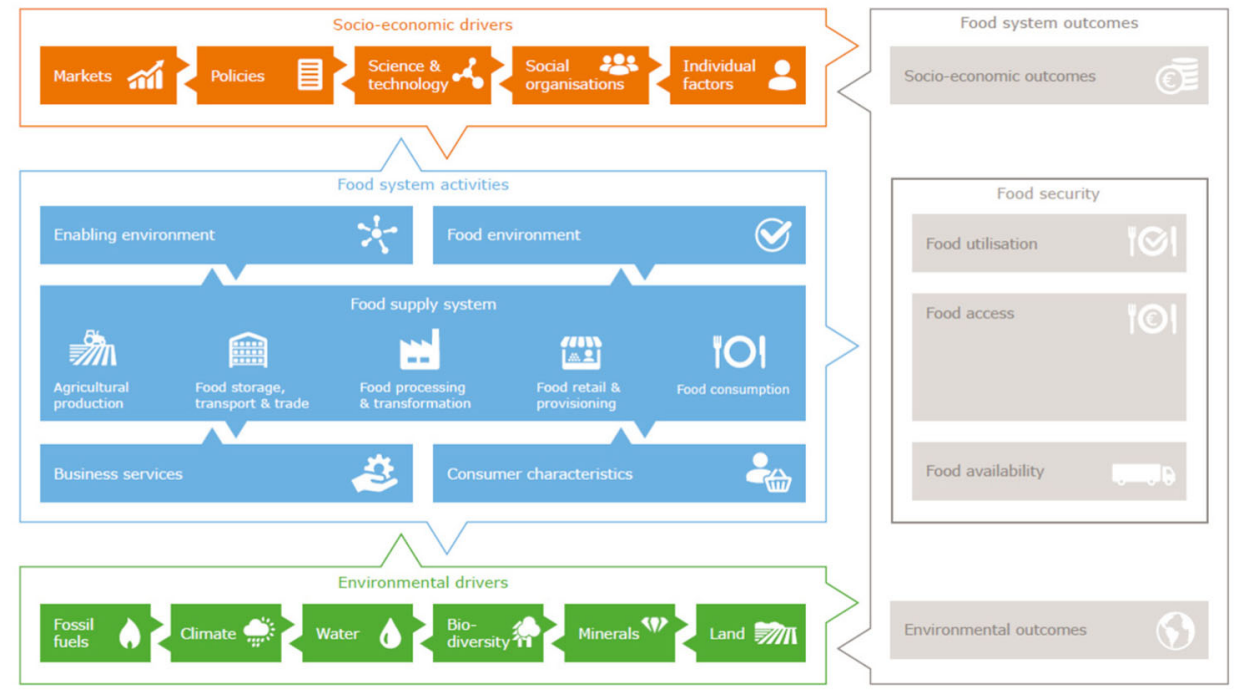

Figure 1 Mapping food systems activities, drivers and outcomes, see Van Berkum et al (2018).

Indicate also the following aspects of the transition:

- Country or region of research project(s)/transition;

- Period of the research projects and of the start of the transition;

- Involvement of WR in the research projects and the transition at stake

Describe the transition in the food system at stake 
Describe the main past drivers that led to the present system. These can be cultural, technological, political, economic, social, institutional, legal, etc. To mention a few:

- Policies or strategies to become independent for food supply;

- Policies or strategies to increase exports;

- Policies to stimulate modernisation, mechanisation;

- (Big) companies with deliberate strategies to achieve specific goals;

- Traditional dependence on smallholders;

- Traditional strategies to achieve food security.

\section{Characterisation of the case in MLP terms (2 pages)}

We have chosen to use the 'multi-level perspective' (MLP) on transitions as the overarching framework for the project. The MLP distinguishes three levels: niches, regime and landscapes. For the niche and regime level, the MLP uses three key dimensions, viz. actors, technologies and institutions.

The levels are briefly described as follows:

Regime: this is the agro-food system that you study, e.g. the system of vegetable production and consumption in Tanzania.

- Niche: these are alternatives to (parts of) the present system that are still under development or used only on a small scale. When these niches would 'break through' (e.g. by widespread adoption or changes in regulatory framework) they could transform the system.

- Landscape: these are broader factors that can put pressure on the present regime for change and/or stimulate the development of niches. This may include, for instance, policies to $\mathrm{Curb}^{\mathrm{CO}} \mathrm{O}_{2}$ emissions, policies to develop an independent food supply, general policies to alleviate poverty, etc.

We ask you to describe your case under the three subsections below.

\section{The regime}

Here you describe the main features of the system in your case. With a system we mean the food system or part of it, i.e. a system that addresses the production side of food and food products (products) as well as the consumption side (diets). Even if your case focuses on the production side, e.g. new forms of agriculture, beware that this can also have implications for the food processing and distribution that follows and the food consumption or diets. To be able to assess how the system develops and how changes may occur we therefore need to analyse the whole system.

In your description of the system we invite you to discuss the three main dimensions, i.e.

- the technologies used (including infrastructures). This can include all kinds of advanced machinery or very low-tech apparatus. It also includes science based practices like specific forms of crop protection, use of fertilizers, etc. Various technologies are used in the production, the processing and distribution of food.

Describing these technologies can be endless. Focus on those ones that you think are very characteristic or defining for the system that you describe.

- The institutions that 'rule' the system. Institutions can either be formal rules (e.g. policies, agreements between specific parties) or informal rules (e.g. generally accepted norms and (cultural) values).

- The actors that make up the system. These actors should be described in terms of their role in the system (e.g. as food producer, processor, consumer, regulator, etc.) and their relation with the technologies and institutions. Some actors, for instance, may strongly rely on specific technologies or be strongly related to specific institutions while for other these may be less relevant. Such relations are important to be able to analyse which parts of the system may be more or less difficult to change.

You are invited to use all three of these dimensions in a way that you think provides a good description of the system that you analyse. 


\section{Niches $^{5}$}

Niche describes alternatives to (parts of) the present system that are still under development or used only on a small scale. Niches often try to address weaknesses in the present system, e.g. poor sustainability performance. Examples can be new practices in vegetable growing, or low input growth methods, new forms of cooperation between farmers, new outlets of food (supermarkets, specialty restaurants like vegan or vegetarian restaurants) etc. These examples show that niches can target all three dimensions of the MLP, i.e. new agronomic practices/technologies, new social relations or new institutions. We therefore ask you to describe these niches in terms of these three dimensions, i.e. in terms of

1. the new technologies used (including infrastructures). New technologies are used in the production, the processing and distribution of food, such salt-tolerant crops, biofortification, protein technologies.

Describe these new technologies.

2. The new and changing institutions that 'rule' the system. New institutions and the change of roles of institutions, For instance, citizen engagement, adaptive management, new food safety standards etc.

3. The new and changing roles of actors that make up the system. For instance, online supermarket (PicNic), cooperations of farmers.

In relation to a specific food system, there can be a range of niches that seek to change specific parts of it. If there would be many in your case, focus on the ones that could have the largest impact when they would succeed in actually transforming the system.

\section{Landscape}

The landscape is the wider context of a system that can put pressure on the system to change. This can be broad political or societal pressure on issues like climate change, pollution, equity, public health, national economic policy objectives, etc. This is a bit of a garbage can of factors and you are asked to describe a number of these that you think are 'rather strong' in putting pressure on the regime to change or, the opposite, making it difficult for the regime to change. E.g. a specific national economic policy might also favour the current system and make it difficult for alternatives to break through.

\section{Sustainability challenges $(0,5$ page)}

Describe the sustainability challenges in the present system, i.e. those aspect that are currently not sustainable. Here, sustainability is taken in the broad sense, including the variety of UN SDGs, thus addressing climate change, environmental pollution, working conditions, economic well-being, food and nutrition security, public health, etc.

Describe which ones of these are currently not sustainable and elaborate a bit why this is so and how this is related to specific technological, social and/or institutional aspects that you have described above in section 2 . Some challenges may be predominantly technological in nature, while others may be more social or institutional, or a combination of these.

\section{Changing the system $(0,5$ page)}

In this section you should describe what the objectives are of different change actors, i.e. actors deliberately seeking to change the system. These change actors could either be you or a colleague who is working in the case or other change actors from the WUR, an NGO or another agency.

In section 3 you provided a broad overview of sustainability challenges and here you discuss what specific objectives a change actor has. Such specific objectives usually address only a subset of the overall challenge.

Depending on your case, there can be one or more change actors. In some cases, change actors may also be cooperating in a project with a specific objective. Please also indicate such forms of cooperation, if they exist.

\footnotetext{
${ }^{5}$ For operationalization, we can build on 'quick scan approaches'. See e.g.: https://edepot.wur.nl/424282
} 


\section{Assessing barriers for change (0,5 page)}

The TransPath project will focus on exploring transition Pathways. Starting point for these will be the sustainability challenges from section 3 and the change attempts from section 4 . These attempts, however, will face barriers from the present system, e.g. by mismatches in technology, institutional barriers, actors refusing to cooperate or resisting, etc.

In this section you should discuss the most important barriers in your agro-food system for the various change attempts from section 4. Indicate to what extent these barriers are technological, institutional or actor related (i.e. social) or a combination of these. 



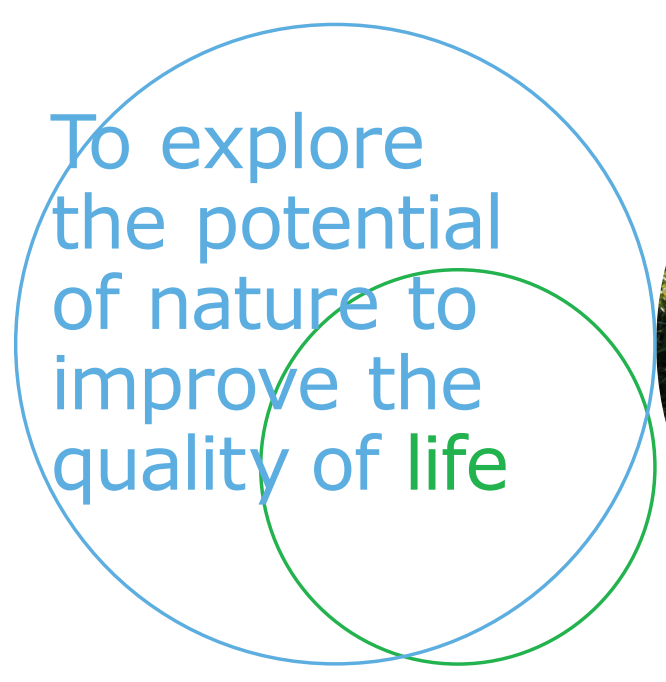

Corresponding address for this report: Wageningen University \& Research | Field Crops P.O. Box 430

8200 AK Lelystad

The Netherlands

T +31 (0)320 291111

www.wur.eu/fieldcrops

Confidential

Rapport WPR-839

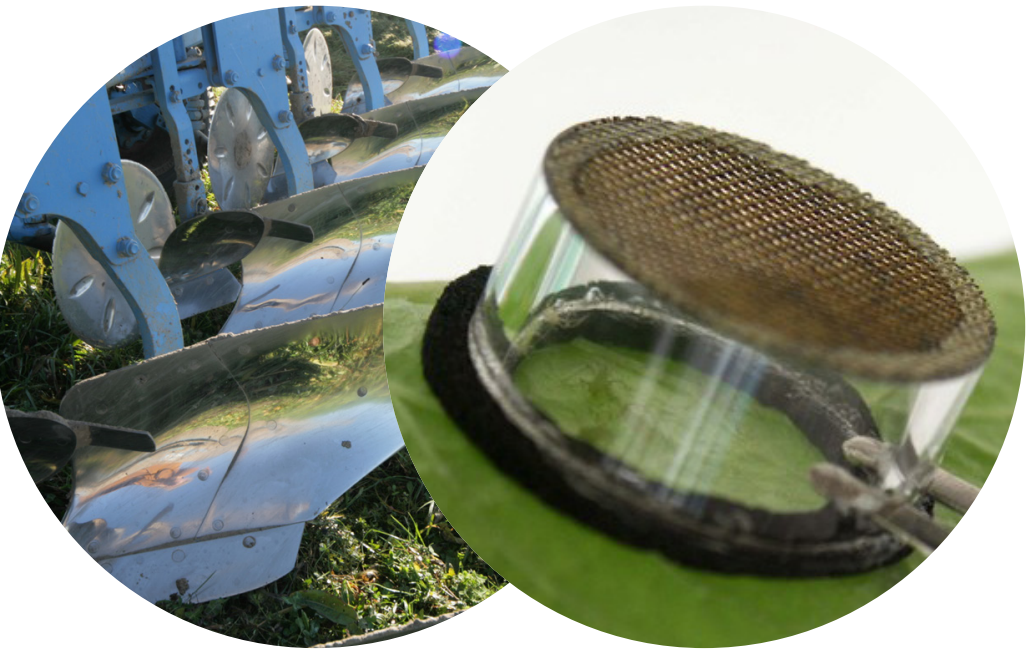

The mission of Wageningen University and Research is "To explore the potential of nature to improve the quality of life". Under the banner Wageningen University \& Research, Wageningen University and the specialised research institutes of the Wageningen Research Foundation have joined forces in contributing to finding solutions to important questions in the domain of healthy food and living environment. With its roughly 30 branches, 5,000 employees and 10,000 students, Wageningen University \& Research is one of the leading organisations in its domain. The unique Wageningen approach lies in its integrated approach to issues and the collaboration between different disciplines. 